\title{
Frontal zones, temperature gradient and depth characterize the foraging habitat of king penguins at South Georgia
}

\author{
Annette Scheffer ${ }^{1,2, *}$, Charles-André Bost ${ }^{2}$, Philip N. Trathan ${ }^{1}$ \\ ${ }^{1}$ British Antarctic Survey, National Environment Research Council, High Cross, Madingley Road, Cambridge CB3 0ET, UK \\ ${ }^{2}$ Centre d'Etudes Biologiques de Chizé, CEBC-CNRS UPR 1934, 79360 Villiers-en-Bois, France
}

\begin{abstract}
Investigating the responses of marine predators to oceanographic structures is of key importance for understanding their foraging behaviour and reproductive success. Using Global Positioning System (GPS) and Time-Depth-Temperature-Recorder (TDR) tags, we investigated how king penguins breeding at South Georgia explore their foraging area over the summer season in both the horizontal and vertical dimensions. We determined how horizontal habitat use may relate to different Antarctic Circumpolar Current (ACC) frontal zones and associated thermal structuring of the water column. To study the penguins' use of the water column, we examined foraging niches defined by temperature, temperature gradient and depth, and explored the importance of these thermal properties for prey pursuit. King penguins foraged within the Polar Front (PF) and its southern edges during incubation, and the Antarctic Zone (AAZ) and Southern ACC Front (SACCF) during brooding. Foraging niches became more distinct with the advancing summer season, defined by strong thermal gradients at shallow depths in the AAZ, and weak gradients at greater depths in the SACCF. These niches indicate foraging in the sub-thermocline Winter Water (WW) in the AAZ, and in deep WW and Circumpolar Deep Water (CDW) at the SACCF. The influence of different ACC frontal zones in the area to the north of South Georgia appears to provide for a horizontally and vertically segregated environment. The presence of optional foraging areas and niches close to the colony clearly play an important role in these king penguins' foraging success.
\end{abstract}

KEY WORDS: Aptenodytes patagonicus - Hydrological structure · Antarctic Circumpolar Current $\cdot$ Temperature gradient $\cdot$ Foraging niche $\cdot$ Seabird

Resale or republication not permitted without written consent of the publisher

\section{INTRODUCTION}

The behaviour and distribution of marine predators are generally thought to be determined by the location of their prey, but influenced by specific time and energy constraints. Prey distribution is strongly influenced by the structure of the marine environment (Owen 1981, Franks 1992), which is determined by physical properties such as temperature and temperature gradient. They govern the concentration of nutrients in the water column (Lima et al. 2002), which in turn influence the distribution and abun- dance of planktonic organisms and, hence, higher trophic levels including the prey of apex predators (Owen 1981, Lutjeharms 1985, Schneider 1990). Surface features such as oceanographic fronts arise from where different water masses meet (Schneider 1990), and are, therefore, locations where different habitats as well as strong physical gradients occur in a spatially restricted area. Such a heterogeneous environment may be crucial for the existence of distinct foraging niches for predators.

King penguins are one of the most important avian consumers in the Southern Ocean (Woehler 1995). 
They feed mainly on myctophids (Cherel \& Ridoux 1992, Olsson \& North 1997), mesopelagic fish that are generally associated with particular water masses or temperature ranges (Hulley 1981, Kozlov et al. 1991, Collins et al. 2012, Fielding et al. 2012), as well as with fronts and related oceanographic features (Brandt et al. 1981, Kozlov et al. 1991, Pakhomov et al. 1996, Rodhouse et al. 1996). Among diving birds, king penguins are able to forage at depths of over 300 $m$ (Charrassin et al. 2002), and are known to use thermal discontinuities for foraging (Charrassin \& Bost 2001). However, we still have little detailed understanding about how these predators may explore the thermal structure of the water column in different marine environments, and how habitat use may be adjusted depending upon changing constraints.

King penguins experience changing time and energy constraints over the summer breeding season (Charrassin et al. 2002, Halsey et al. 2010). During incubation (December to February), each parent alternately incubates and then returns to sea to restore its body reserves in 2 to $3 \mathrm{wk}$ long foraging trips (Bost et al. 1997). After hatching, chick rearing (February to March) causes increased energy demand since the chick must be provisioned regularly (Charrassin et al. 1998). It is likely that changes in foraging behaviour reflect how these predators access the most profitable oceanographic structures according to their time and energy constraints. In this context, the thermal structuring of the foraging area and the presence of different foraging niches may play an important role (Charrassin \& Bost 2001).

South Georgia is situated within the Antarctic Circumpolar Current (ACC), the most pronounced feature of the Southern Ocean circulation (Rintoul et al. 2001). It includes 3 major deep-reaching fronts, from north to south, the SubAntarctic Front (SAF), the Polar Front (PF) and the southern ACC Front (SACCF) (Orsi et al. 1995). The PF is an important foraging area for incubating king penguins at South Georgia (Trathan et al. 2008, Scheffer et al. 2010). However, there is no information on how changing breeding constraints may affect foraging behaviour, and how this may relate to local oceanography. For king penguins, foraging areas close to the SACCF have not yet been considered, despite the key role of this front for the Scotia Sea ecosystem (Thorpe et al. 2002, 2004, Ward et al. 2002, Murphy et al. 2004) and its close proximity to the breeding colonies at South Georgia. We know very little about features in the vertical dimension that may restrict efficient foraging for diving predators such as king penguins, or how this may relate to any changing constraints for these birds. Identifying such features and their association with different oceanographic areas may increase our understanding of how horizontal habitat use by diving predators is related to their exploration of the water column. This may be of importance in the context of environmental change, and any future potential effects on king penguin populations (Le Bohec et al. 2008, Forcada \& Trathan 2009, Péron et al. 2012).

We investigated how king penguins breeding at South Georgia explore their available foraging area over the summer season in the horizontal and vertical dimensions. Using a combination of Global Positioning System (GPS) tracking and time-depth-temperature recorders (TDR), we addressed the question of how horizontal habitat use may relate to different ACC frontal zones and associated thermal structuring of the water column, and how diving behaviour, presumably targeting particular niches in the water column, changed accordingly. The results are discussed in the context of environmental variability and the potential vulnerability of diving predators such as king penguins to future environmental change.

\section{MATERIALS AND METHODS}

\section{Study area, study period and device deployments}

The study was conducted at the Hound Bay king penguin breeding colony on the northeast coast of South Georgia $\left(54.23^{\circ} \mathrm{S}, 36.15^{\circ} \mathrm{W}\right)$ during the austral summers of 2005 to 2006 and 2006 to 2007 . In total, 17 adult breeding king penguins were tagged: (1) during incubation in December 2005 to January 2006 (Early Incubation, $\mathrm{n}=4$, female), (2) during late incubation in January to February 2007 (Late Incubation, $\mathrm{n}=4$, unknown sex) and (3) during brooding $(\mathrm{n}=9$, unknown sex). Brooding birds were subsequently distinguished into Brooding I and Brooding II based on behaviour (see 'Results').

The horizontal movements of penguins were tracked by Track-Tag GPS loggers (Navsys; further details of Track-Tag are available at www.navsys. com/Products/tracktag.htm), which require only 60 $\mathrm{ms}$ to store raw GPS data. Devices were programmed to record positions at $60 \mathrm{~s}$ intervals and were equipped with a saltwater switch to delay acquisition while birds were under water. Loggers, with batteries and housing, weighed $55 \mathrm{~g}(<0.5 \%$ of body mass $)$ and measured $35 \times 100 \times 15 \mathrm{~mm}(<0.7 \%$ of the cross sectional area of the body). Diving behaviour was recorded by TDR (Wildlife Computers). TDR devices 
were programmed to record depth and water temperature at $1 \mathrm{~s}$ intervals when wet. Recordings during surface periods were halted by a saltwater switch and resumed when the bird restarted diving. The resolution of depth recordings was $0.5 \mathrm{~m}$. TDRs weighed $30 \mathrm{~g}(<0.25 \%$ of body mass $)$ and measured $15 \times 100 \times$ $15 \mathrm{~mm}(\mathrm{Mk} 9)$ and $10 \times 90 \times 20 \mathrm{~mm}(\mathrm{Mk} 7)(<0.5 \%$ of the cross sectional area of the body). Of the 17 penguins equipped with GPS devices, 13 of them had Mk9 TDR with external fast-responding temperature sensors, 2 had Mk7 TDR and 2 were without TDR devices. Devices were attached using methods modified from Wilson et al. 1997. All devices were recovered after a single foraging trip (varying between 5 and 23 d). In 2007, all tracked birds were weighed before leaving for sea and after their return to land to determine body mass gain during the foraging trips.

\section{Oceanography of the study area}

South Georgia is a sub-Antarctic island situated within the path of the ACC, with the PF to the north and the SACCF close to the island (Fig. 1). In contrast to most other king penguin breeding colonies which are located north of the PF (Bost et al. 2009), South Georgia is situated south of the PF. The PF is commonly defined as the location where cold Antarctic subsurface waters sink below warmer sub-Antarctic

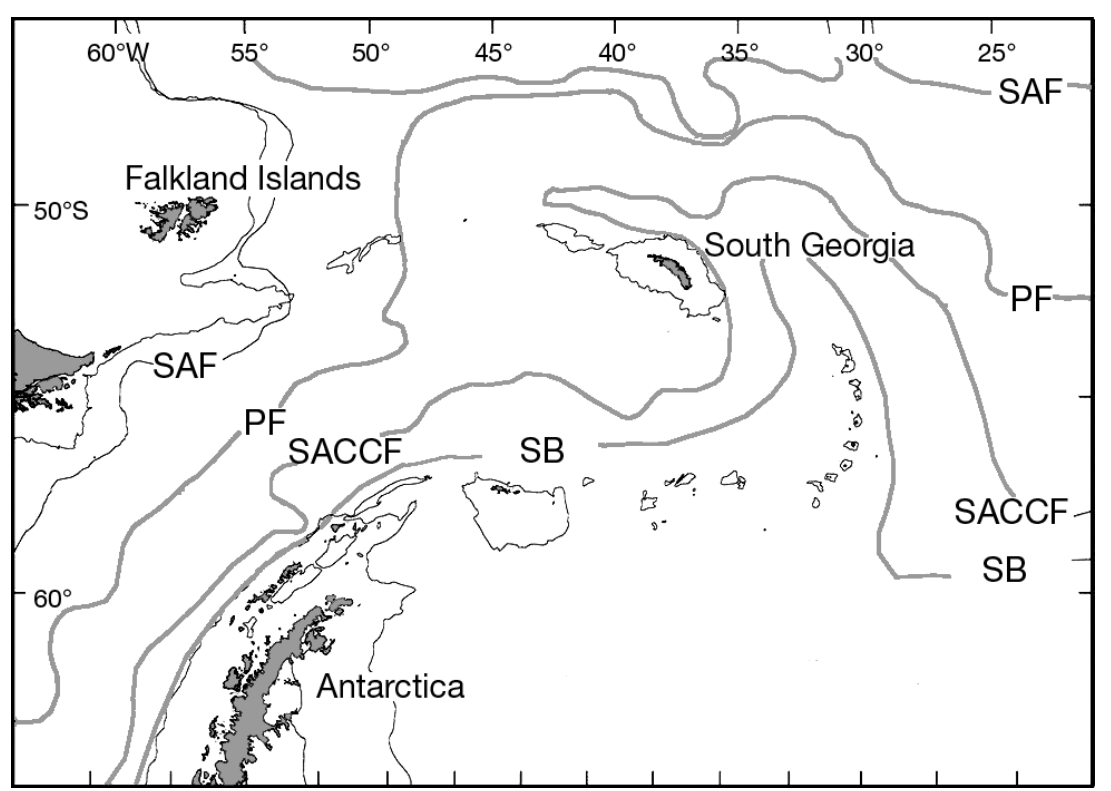

Fig. 1. South Georgia and the Antarctic Circumpolar Current (ACC) frontal positions in the Scotia Sea. Fronts: thick grey lines; $500 \mathrm{~m}$ and $1000 \mathrm{~m}$ isobaths: dark grey. Frontal positions from Orsi et al. (1995). SAF: Sub-Antarctic Front; PF: Polar Front; SACCF: Southern ACC Front; SB: Southern ACC Boundary waters (Deacon 1933), corresponding to the northernmost extent of the subsurface temperature minimum, $<2^{\circ} \mathrm{C}$ near $200 \mathrm{~m}$ depth (Belkin \& Gordon 1996). The flow regime close to South Georgia is dominated by the SACCF, which loops anticyclonically around the South Georgia peri-insular shelf before retroflecting north of the island (Orsi et al. 1995, Thorpe et al. 2002, Meredith et al. 2003) at $\sim 36^{\circ} \mathrm{W}$. The SACCF flow is rich in nutrients (Ward et al. 2002), and hosts high biomass of zooplankton (Murphy et al. 2004). The Antarctic Zone (AAZ) is situated between the PF and the SACCF; it is characterized by the meeting of cold Antarctic waters and warmer surface waters from the PF. A complex eddy field has been described in the AAZ north of South Georgia as well as a warm-core anticyclonic circulation at around $52^{\circ} \mathrm{S}, 35^{\circ} \mathrm{W}$ (Meredith et al. 2003). Recent definitions of ACC fronts and zones in terms of Sea Surface Height (SSH) allow the identification of such features from altimetry data (Sokolov \& Rintoul 2009, Venables et al. 2012), and the assignation of specific thermal profiles to frontal zones (Venables et al. 2012). In the Scotia Sea, the vertical structure of the water column includes the Surface Mixed Layer (SML), and the underlying cold Winter Waters (WW) originating from the previous winter mixed layer. The SML and WW are separated by a thermocline, a strong vertical temperature gradient of variable extent and intensity. Below the WW layer (from $\sim 250$ to $300 \mathrm{~m}$ ), temperatures rise towards $2^{\circ} \mathrm{C}$, characterizing the Circumpolar Deep Water (CDW).

\section{Oceanographic data}

SSH data

Changes in SSH encountered by the penguins over their foraging trips were analyzed using Aviso (www.aviso.oceanobs.com) absolute dynamic topography (ADT) data. We used Near-real time (NRT) data available at a higher temporal resolution than the delayed time (DT) products. Data were available at a spatial resolution of $1 / 3^{\circ} \times 1 / 3^{\circ}$ and a biweekly temporal resolution. $\mathrm{SSH}$ values at each dive location were estimated by searching for the geographically nearest value within the corresponding dataset. 


\section{Vertical temperature data}

Vertical temperature values were obtained from the external Mk9 sensor data after applying appropriate temperature correction factors from the device calibration data sheets (Wildlife Computers). Mk7 temperature data were not used due to long response times of the internal temperature sensors. Mk9 temperature sensors provide high quality data (accuracy $0.1^{\circ} \mathrm{C} \pm 0.05^{\circ} \mathrm{C}$, Simmons et al. 2009), and were, therefore, used for determining the properties of the water column encountered during the penguins' dives. To compensate for the surface heating effect by direct sun exposure and penguin body temperature on the temperature sensors (McCafferty et al. 2007), temperature values collected between 0 and $10 \mathrm{~m}$ were replaced by the value measured at $10 \mathrm{~m}$ depth during the ascent. The vertical water temperature gradient for each recorded depth point was also calculated; this was estimated as the temperature difference between $25 \mathrm{~m}$ above and $25 \mathrm{~m}$ below the given depth point. Temperature gradients near to the depth extremes of a dive were calculated using the maximal depth range possible (limited by the surface for points $<25 \mathrm{~m}$ depth, and by the maximal dive depth for points >max. depth $25 \mathrm{~m}$ ). The resulting possible bias in gradient values may only affect the depth range between the maximum depth range of a dive and $25 \mathrm{~m}$ above, as dives $<50 \mathrm{~m}$ were not considered for analyses of foraging behaviour (see Data analysis). A temperature gradient of 1 thus corresponds to a temperature increase of $1^{\circ} \mathrm{C}$ per $50 \mathrm{~m}$ depth, -1 to a temperature decrease of $1^{\circ} \mathrm{C}$ per $50 \mathrm{~m}$.

\section{Data analysis}

Data analyses were performed using Matlab (MathWorks) and the custom-made software MultiTrace (Jensen software systems).

\section{Analysis of surface and diving behaviour}

GPS data were filtered to remove positions with navigation class $>2$, where class categories were 0 : good, 1: altitude aided, 2: marginal position dilution of precision, and 3: bad. For each bird, we calculated trip duration, distance covered, max. distance from the colony and the furthest latitude south reached. Exact departure and return times from and to the island were determined from the TDR data. A foraging zone coefficient (FZC) was calculated as the total trip length $(\mathrm{km})$ divided by the max. distance from the colony $(\mathrm{km})$ (modified from Guinet et al. 1997, Hull et al. 1997), indicating the degree of directness or looping of a foraging trip.

A zero offset correction was applied on the dive data. Only dives $>50 \mathrm{~m}$ depth were used for analysis, as they were considered to represent the majority of king penguins foraging dives (Pütz et al. 1998, Charrassin et al. 2002). Diving behaviour was analysed by calculating the following dive parameters: dive depth, dive duration, bottom duration (the time between the first and last wiggle or dive step deeper than $75 \%$ of the maximum dive depth, following Halsey et al. 2007), the number of wiggles (deviations $>1 \mathrm{~m}$ of depth with an absolute vertical instant $>0$ ) as a proxy of feeding success (Bost et al. 2007) and broadness index (bottom duration:dive duration, indicating the proportion of a dive used for the bottom period, see Halsey et al. 2007 for more details). Furthermore, we determined the total vertical distance travelled per day, the dive frequency, the percentage of submerged time compared to the total time at sea, and the percentage of submerged time spent at depths $>150 \mathrm{~m}$ as proxies of foraging effort. As king penguins are visual feeders and essentially forage during the daylight and twilight hours (Bost et al. 2002), night dives were excluded from the analyses. Exact sunrise and sunset times were calculated as described in Scheffer et al. 2010. Geographical coordinates at the start of each dive were interpolated based on time from the GPS data, assuming straight line travel and constant speed between 2 location points (Weavers 1992).

Principal Component Analysis (PCA) was carried out on 15 variables characterizing foraging behaviour (surface movements and diving behaviour, see Table 1 for the complete listing of all PCA variables), allowing identification of the main variables accounting for differences in foraging behaviour as well as behavioural groupings of birds. Dive parameters among grouped birds were compared using Kruskal-Wallis statistics as tests for normality failed (Jarque Bera test) and transformations did not help the data to conform to the normality assumption. When significant differences were found among groups, an all pairwise multiple comparison (Dunn's method) was performed to determine the groups that differed from the others.

Analysis of horizontal and vertical habitat use

The horizontal habitat use of king penguins was analysed with respect to trip orientation relative to 
Table 1. Principal component analysis of the foraging parameters. Component loadings of the different variables

\begin{tabular}{|lcc|}
\hline Variable & PC1 (75.7\%) & PC2 $(21.8 \%)$ \\
\hline Dive depth & 0.1717 & 0.1133 \\
Dive duration & 0.0551 & 0.0456 \\
Bottom duration & -0.0868 & -0.2066 \\
No. wiggles/dive & -0.0613 & -0.3846 \\
Dive frequency & -0.0812 & -0.2237 \\
\% time submerged & 0.0498 & -0.0957 \\
\% time submerged $>150 \mathrm{~m}$ & 0.5444 & 0.3738 \\
No. wiggles:time submerged & -0.0718 & -0.5024 \\
No. wiggles:bottom duration & 0.0217 & -0.1862 \\
Depth range index & -0.0336 & -0.1832 \\
Broadness index & -0.1306 & -0.2522 \\
Vertical distance:day & 0.1422 & -0.0198 \\
Trip duration & -0.4662 & 0.3432 \\
Trip length & -0.487 & 0.2627 \\
Max. distance from colony & -0.3902 & 0.1557 \\
\hline
\end{tabular}

the different ACC fronts. The ACC fronts and zones were defined based on SSH signatures following Venables et al. (2012). The penguin's vertical habitat use was analysed with respect to the exploration of depth and thermal properties of the water column relative to the ACC fronts. We considered the bottom phases of dives, which is thought to be the most important phase for prey capture (Charrassin et al. 2002, Simeone \& Wilson 2003, Ropert-Coudert et al. 2006). Kernel density estimations of bottom periods of the different foraging groups were computed on SSH and depth using a Gaussian Kernel. These were then overlaid on the vertical thermal structure of different ACC frontal zones following Venables et al. 2012. This allowed us to analyse the penguins' use of the water column with respect to depth and thermal structures relative to frontal zones.

Detailed use of the water column by the penguins while foraging was analysed by considering depth, temperature and temperature gradient during the bottom periods of the dives. Analyses were carried out on data with a resolution of $1 \mathrm{~Hz}$. Contour plots of bottom periods of dives $>50 \mathrm{~m}$ on depth - temperature gradient and temperature - temperature gradient axes allowed us to evaluate the penguins' use of the water column, and to identify the target of different water masses by the different foraging groups. To identify water masses from the water characteristics targeted by the penguins, we defined 4 water masses based on water temperature ( $\mathrm{T}$ ) and temperature gradient $(\operatorname{gradT})$ : thermocline waters $(\mathrm{T} \geq 1.5 ; \operatorname{grad} \mathrm{T}<0)$, WW in proximity $\leq 25 \mathrm{~m}$ of the thermocline $(\mathrm{T}<1.5 ;$ grad $\mathrm{T}<0)$, WW deeper than $25 \mathrm{~m}$ below the thermocline $(\mathrm{T}<1.5 ;$ grad $\mathrm{T} \geq 0)$, CDW $(\mathrm{T} \geq 1.5 ;$ grad $\mathrm{T} \geq 0)$.

\section{Wiggles occurrence and influencing factors}

As wiggles are good proxies of prey capture attempts in penguins (Takahashi et al. 2004, Bost et al. 2007, Hanuise et al. 2010), we examined water characteristics where wiggles occurred, with respect to temperature and temperature gradient. We used logistic regression models to quantify relationships between water properties and the occurrence of wiggles for individual as well as for grouped birds. For the regression models, we included temperature and temperature gradient data for dives $>50 \mathrm{~m}$ depth with a temporal resolution of $1 \mathrm{~s}$, after testing for noncorrelation using Pearson's correlation coefficient. The predictor of wiggles occurrence was a combination of the water temperature, the values and the absolute values of the temperature gradient, taking into account the direction of the gradient as well as its intensity. To evaluate model discrimination performances between wiggle presence and absence, we used risk score plots (Royston \& Altman 2010). Risk score plots allowed us to graphically compare the densities of the risk score (linear predictor) in the event and no-event group (occurrence and nonoccurrence of wiggles). The overlap of the risk score densities determined the discrimination performance of the model: the larger the overlap, the weaker the discrimination.

\section{RESULTS}

\section{Identification of different foraging groups}

We distinguished 4 foraging groups characterized by differences in breeding stage as well as foraging characteristics (Fig. 2, Tables 1, 2 \& 3). The groups were Early Incubation $(n=4)$, Late Incubation $(n=4)$, Brooding I $(n=3)$ and Brooding II $(n=4)$. The PCA of foraging parameters showed the separation of the 4 foraging groups, and allowed the identification of the main variables accounting for the differences (Fig. 2, Table 1). The first principal component was mainly explained by the horizontal and vertical distances travelled. These variables separated the Brooding II from the Incubation groups, with the Brooding I birds spread out in between. Brooding II birds were characterized by the shortest horizontal (Table 2) and 


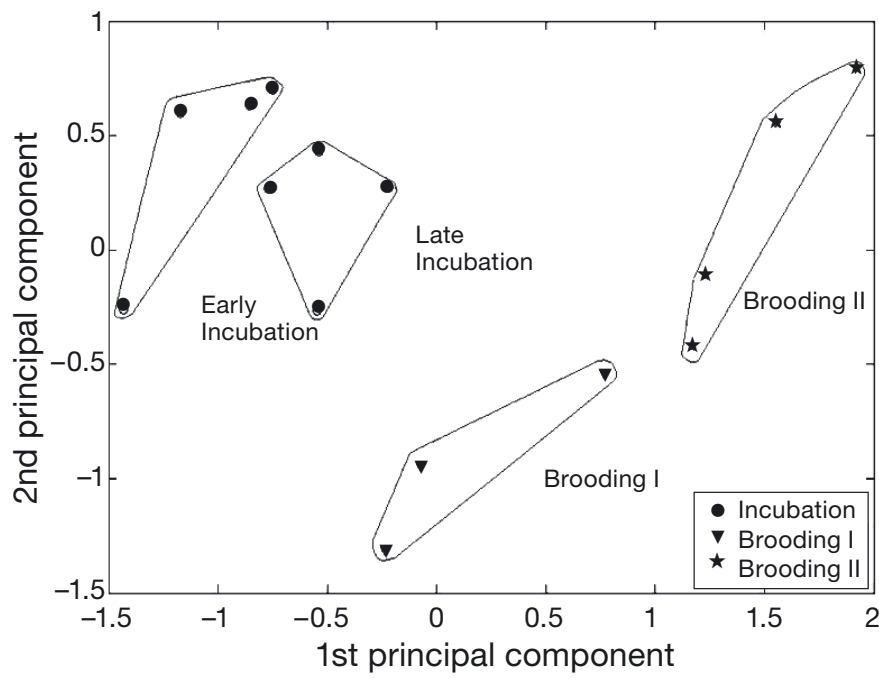

Fig. 2. Aptenodytes patagonicus. Principal component analysis of the foraging parameters in the different foraging groups.

Component loadings of the variables are listed in Table 1

longest daily vertical (Table 3) distances travelled. The second principal component was mainly loaded with variables of underwater foraging behaviour, separating the Brooding I birds from the Incubation and Brooding II groups. Brooding I birds were characterized by a dominant bottom phase, high wiggle numbers and a high dive frequency (Table 3). Brooding II birds showed the deepest and longest dives with the shortest bottom periods (Table 3). Broadness index was highest for Brooding I birds and lowest for Brooding II birds (Table 3). A main variable influencing both principal components was the proportion of dive time spent at depths $>150 \mathrm{~m}$, separating the Brooding II birds from the Incubation and Brooding I groups (Fig. 2, Table 1).

\section{Trip orientation and foraging areas}

All trips were oriented to the north towards the SACCF, AAZ and PF waters, with birds of different breeding stages targeting different foraging areas (Fig. 3) and showing different foraging trip characteristics (Table 2). Early Incubation birds undertook the most extended foraging trips, where increased SSH values indicated PF and Polar Frontal Zone (PFZ) waters. Late Incubation birds targeted areas at the southern edge of the PF and in the AAZ.

Table 2. Aptenodytes patagonicus. Trip parameters for individual birds in the different foraging groups $(\mathrm{FZC}=\mathrm{foraging}$ zone coefficient)

\begin{tabular}{|c|c|c|c|c|c|c|}
\hline Bird ID & $\begin{array}{l}\text { Date of deployment } \\
\text { and recovery }\end{array}$ & $\begin{array}{l}\text { Trip duration } \\
\text { (d) }\end{array}$ & $\begin{array}{l}\text { Trip length } \\
(\mathrm{km})\end{array}$ & $\begin{array}{l}\text { Max. distance } \\
\text { from colony }(\mathrm{km})\end{array}$ & $\begin{array}{l}\text { Min. }{ }^{\circ} \mathrm{S} \\
\text { reached }\end{array}$ & FZC \\
\hline \multicolumn{7}{|c|}{ Early Incubation } \\
\hline 8 & $23.12 .2005-13.01 .2006$ & 19.9 & 2077 & 642 & 49.84 & 3.2 \\
\hline 9 & $28.12 .2005-18.01 .2006$ & 19.5 & 2291 & 522 & 49.77 & 4.4 \\
\hline 10 & $30.12 .2005-17.01 .2006$ & 16.4 & 1880 & 520 & 49.83 & 3.6 \\
\hline 11 & $30.12 .2005-23.01 .2006$ & 23.2 & 2510 & 537 & 49.73 & 4.7 \\
\hline Mean $\pm \mathrm{SE}$ & & $19.7 \pm 1.4$ & $2190 \pm 136$ & $556 \pm 29$ & $49.79 \pm 0.03$ & $4.0 \pm 0.3$ \\
\hline \multicolumn{7}{|c|}{ Late Incubation } \\
\hline C5 & 02.02.2007-20.02.2007 & 17.3 & 1585 & 435 & 50.77 & 3.7 \\
\hline $\mathrm{C} 7$ & $02.02 .2007-2.02 .2007$ & 20.3 & 1506 & 409 & 50.72 & 3.7 \\
\hline C9 & $03.02 .2007-26.02 .2007$ & 23.2 & 1690 & 558 & 51.82 & 3.0 \\
\hline $\mathrm{C} 10$ & $03.02 .2007-17.02 .2007$ & 13.4 & 1150 & 445 & 50.40 & 2.6 \\
\hline Mean $\pm \mathrm{SE}$ & & $18.6 \pm 2.1$ & $1483 \pm 117$ & $462 \pm 33$ & $50.93 \pm 0.31$ & $3.2 \pm 0.3$ \\
\hline \multicolumn{7}{|l|}{ Brooding I } \\
\hline H5 & $09.02 .2007-17.02 .2007$ & 6.1 & 610 & 234 & 52.55 & 2.6 \\
\hline H9 (no TDR) & $12.02 .2007-19.02 .2007$ & 6.2 & 559 & 227 & 52.5 & 2.5 \\
\hline P3 & $18.02 .2007-01.03 .2007$ & 9.1 & 925 & 317 & 51.67 & 3.1 \\
\hline P5 & 18.02.2007-28.02.2007 & 7.0 & 822 & 346 & 51.32 & 2.9 \\
\hline Mean $\pm \mathrm{SE}$ & & $7.1 \pm 0.7$ & $729 \pm 87$ & $281 \pm 30$ & $52.01 \pm 0.31$ & $2.8 \pm 0.1$ \\
\hline \multicolumn{7}{|l|}{ Brooding II } \\
\hline H3 & $09.02 .2007-16.02 .2007$ & 5.1 & 491 & 190 & 52.98 & 2.6 \\
\hline H6 (no TDR) & $10.02 .2007-16.02 .2007$ & 5.5 & 490 & 159 & 53.04 & 3.1 \\
\hline $\mathrm{P} 4$ & $18.02 .2007-25.02 .2007$ & 6.0 & 517 & 163 & 53.50 & 3.2 \\
\hline P10 & $27.02 .2007-04.03 .2007$ & 4.8 & 430 & 112 & 53.44 & 3.9 \\
\hline $\mathrm{T} 4$ & $28.02 .2007-06.03 .2007$ & 5.5 & 629 & 247 & 52.20 & 2.4 \\
\hline Mean $\pm \mathrm{SE}$ & & $5.4 \pm 0.2$ & $512 \pm 33$ & $174 \pm 22$ & $53.03 \pm 0.23$ & $3.0 \pm 0.3$ \\
\hline
\end{tabular}


Table 3. Aptenodytes patagonicus. Dive parameters for individual birds in the different foraging groups. KW = Kruskal Wallis test with $\mathrm{p}<0.001$. Dunn's test was performed with $\mathrm{p}<0.05$. The foraging groups show significant differences from others as indicated (all: all other foraging groups; Inc: Early \& Late Incubation; BI: Brooding I; BII: Brooding II). VD = vertical distance

\begin{tabular}{|c|c|c|c|c|c|c|c|c|}
\hline Bird ID & $\begin{array}{l}\text { Dive depth } \\
\text { (m) }\end{array}$ & $\begin{array}{c}\text { Dive } \\
\text { duration (s) }\end{array}$ & $\begin{array}{c}\text { Bottom } \\
\text { duration (s) }\end{array}$ & $\begin{array}{l}\text { Wiggles } \\
\text { per dive }\end{array}$ & $\begin{array}{l}\text { Broadness } \\
\text { index }\end{array}$ & $\begin{array}{l}\text { Total VD } \\
\left(\mathrm{km} \mathrm{d}^{-1}\right)\end{array}$ & $\begin{array}{l}\text { Total dives } \\
\text { per day }\end{array}$ & $\begin{array}{l}\% \text { of time sub- } \\
\text { merged }>150 \mathrm{~m}\end{array}$ \\
\hline \multicolumn{9}{|l|}{ Early Incubation } \\
\hline 8 & 117.8 & 246.5 & 61.6 & 6.3 & 0.26 & 306.5 & 268.5 & 2.3 \\
\hline 9 & 130.2 & 259.0 & 73.1 & 8.0 & 0.28 & 306.2 & 209.4 & 4.7 \\
\hline 10 & 129.0 & 287.4 & 92.2 & 9.1 & 0.32 & 266.1 & 171.0 & 3.5 \\
\hline 11 & 126.0 & 260.5 & 82.6 & 12.4 & 0.32 & 301.8 & 583.0 & 3.4 \\
\hline Mean $\pm \mathrm{SE}$ & $125.7 \pm 2.8$ & $263.3 \pm 8.6$ & $77.4 \pm 6.6$ & $9.0 \pm 1.3$ & $0.30 \pm 0.02$ & $295.1 \pm 9.7$ & $308.0 \pm 93.8$ & $3.5 \pm 0.5$ \\
\hline \multicolumn{9}{|l|}{ Late Incubation } \\
\hline C5 & 134.2 & 246.8 & 61.9 & 10.5 & 0.25 & 310.1 & 412.5 & 4.1 \\
\hline $\mathrm{C} 7$ & 128.8 & 260.9 & 73.3 & 7.4 & 0.28 & 315.1 & 249.7 & 4.1 \\
\hline C9 & 144.1 & 258.6 & 54.1 & 7.1 & 0.21 & 297.7 & 261.3 & 4.6 \\
\hline $\mathrm{C} 10$ & 122.5 & 251.4 & 57.8 & 5.7 & 0.23 & 364.2 & 361.5 & 3.1 \\
\hline Mean $\pm \mathrm{SE}$ & $132.4 \pm 4.6$ & $254.4 \pm 3.3$ & $61.8 \pm 4.1$ & $7.7 \pm 1.0$ & $0.24 \pm 0.02$ & $321.8 \pm 14.6$ & $321.2 \pm 39.4$ & $4.0 \pm 0.3$ \\
\hline \multicolumn{9}{|l|}{ Brooding I } \\
\hline H5 & 145.1 & 256.0 & 70.9 & 9.7 & 0.28 & 434.8 & 327.3 & 6.4 \\
\hline P3 & 118.0 & 249.8 & 96.2 & 14.6 & 0.39 & 317.1 & 254.2 & 2.0 \\
\hline P5 & 111.3 & 239.0 & 81.0 & 10.4 & 0.34 & 333.6 & 355.4 & 2.1 \\
\hline Mean \pm SE & $124.8 \pm 10.3$ & $248.3 \pm 4.7$ & $82.7 \pm 7.4$ & $11.6 \pm 1.5$ & $0.33 \pm 0.03$ & $361.8 \pm 36.8$ & $312.3 \pm 30.2$ & $3.5 \pm 1.4$ \\
\hline \multicolumn{9}{|l|}{ Brooding II } \\
\hline H3 & 163.8 & 272.2 & 57.9 & 8.8 & 0.21 & 432.2 & 294.2 & 8.4 \\
\hline P4 & 201.9 & 308.4 & 52.1 & 6.5 & 0.17 & 377.5 & 249.0 & 10.8 \\
\hline P10 & 183.4 & 288.8 & 55.5 & 5.3 & 0.19 & 437.6 & 199.0 & 12.7 \\
\hline $\mathrm{T} 4$ & 175.8 & 294.2 & 68.1 & 11.4 & 0.24 & 424.9 & 366.4 & 9.6 \\
\hline Mean $\pm \mathrm{SE}$ & $181.2 \pm 8.0$ & $290.9 \pm 7.5$ & $58.4 \pm 3.4$ & $8.0 \pm 1.3$ & $0.20 \pm 0.01$ & $418.0 \pm 13.8$ & $277.2 \pm 35.5$ & $10.4 \pm 0.9$ \\
\hline KW \& Dunn's tes & all & BI-BII & BI-BII & $\mathrm{BI}$ & BI-BII & Inc-BI\&BII & BII & BII \\
\hline
\end{tabular}

Brooding birds undertook shorter trips into areas south of the PF. Brooding I birds showed highly directed foraging trips into AAZ waters, indicated by low FZC values. Brooding II birds were characterized by less directed foraging trips into the SACCF or its northern boundary.

\section{Vertical habitat use}

Penguins in the different foraging groups showed differing use of the water column in the various ACC zones (Fig. 4), targeting different depths, water temperatures and temperature gradients during the bottom periods of the dives (Fig. 5). Early Incubation birds foraged in the SACCF, the AAZ, the PF and occasionally in PFZ waters, and explored a broad temperature range of -1 to $6^{\circ} \mathrm{C}$, with temperature gradients between 0.5 and $-3^{\circ} \mathrm{C}$ per $50 \mathrm{~m}$. The thermocline and WW appeared to be the most important water masses for bottom times, but there was no clear concentration of bottom times in specific parts of the water column. Late Incubation birds foraged in the
SACCF and in the AAZ until the southern edge of the $\mathrm{PF}$. Bottom periods were directed into waters of -0.5 to $2^{\circ} \mathrm{C}$ and temperature gradients of up to $-4^{\circ} \mathrm{C}$ per $50 \mathrm{~m}$. Shallow and deep WW were the most targeted water masses. Brooding I birds showed highly focused targeting of shallow waters of strong thermal gradients in the AAZ. Bottom periods were directed into similar conditions to those of Late Incubating birds, but more focused on strong gradients in shallow WW. Brooding II birds concentrated their foraging activity in SACCF waters, where they dived to depths of 100 to $300 \mathrm{~m}$. Bottom periods occurred in a restricted range of temperature and temperature gradient of -0.5 to $2^{\circ} \mathrm{C}$ and -0.5 to $0.5^{\circ} \mathrm{C}$ per $50 \mathrm{~m}$, respectively. This indicates the target of deep WW and CDW.

\section{Wiggles occurrence and influencing factors}

For incubating birds, the correlations between wiggle occurrence and water properties were generally weak when considered over an entire foraging trip. 
(a) Early Incubation $2005 / 06(n=4)$

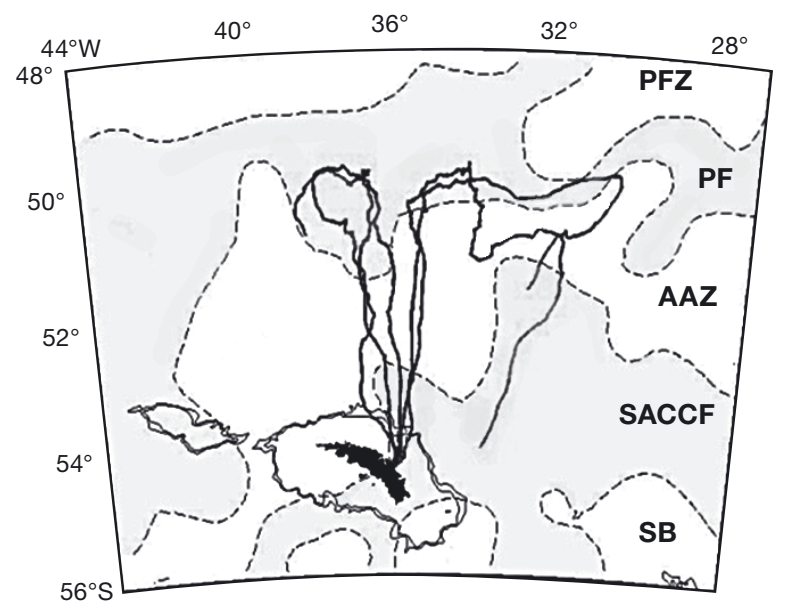

(c) Brooding I $2007(n=4)$

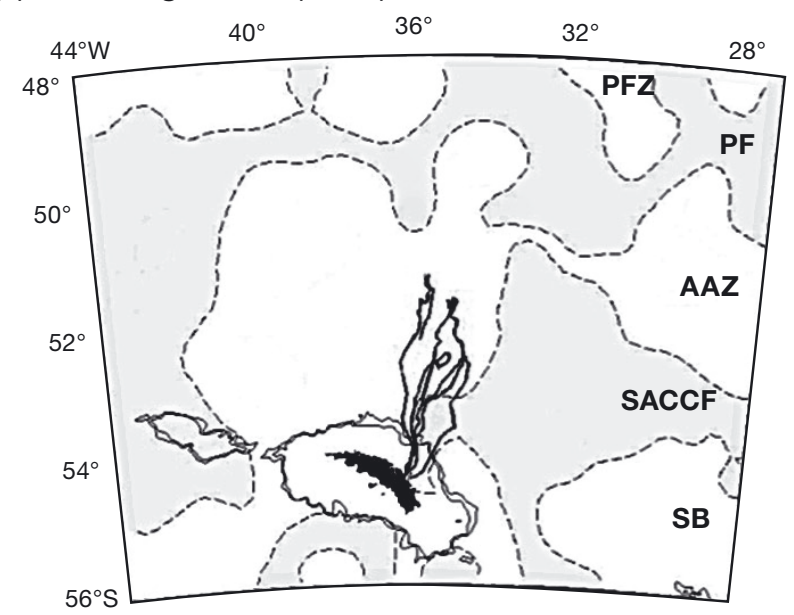

(b) Late Incubation $2007(\mathrm{n}=4)$

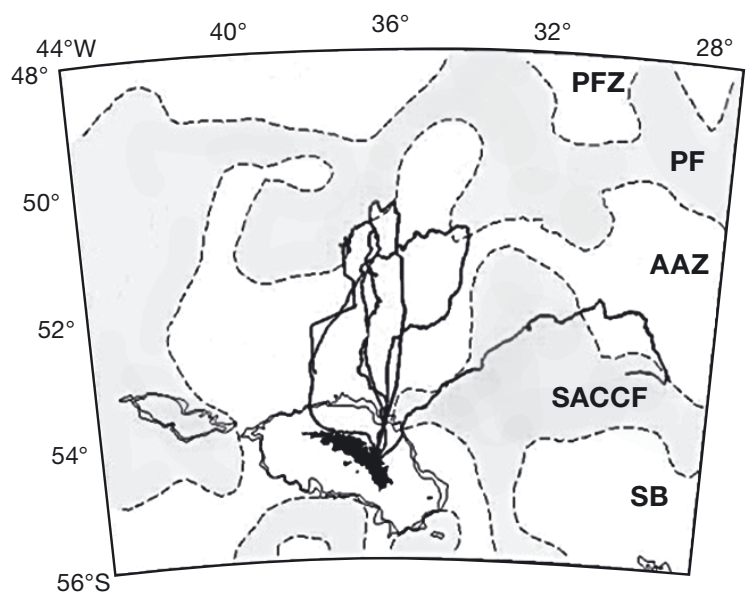

(d) Brooding II $2007(\mathrm{n}=5)$

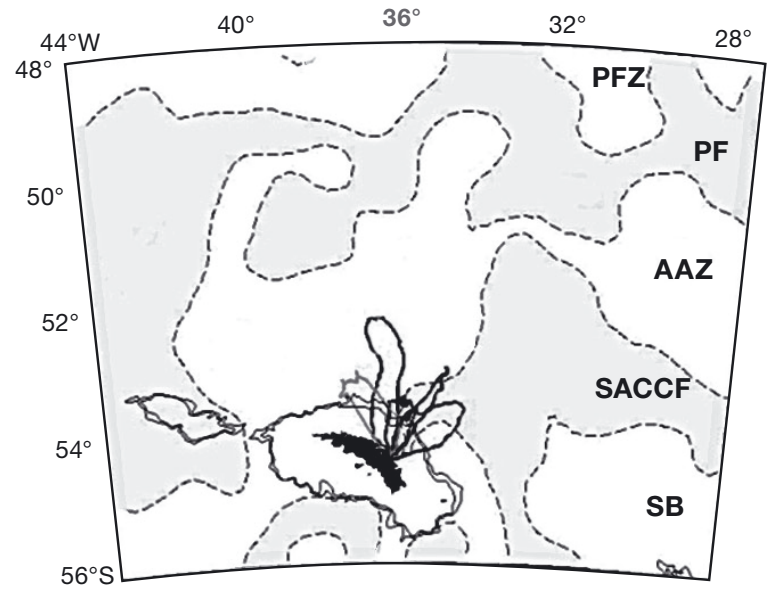

Fig. 3. Aptenodytes patagonicus. Tracks of GPS-equipped individuals (a-d) from South Georgia during summer 2005 to 2006 and summer 2007 with the major ACC fronts in the Scotia Sea. Incomplete tracks are due to tag memory limitations or insufficient time at the surface to collect GPS satellite ephemerides. Frontal zones are based on Sea Surface Height (SSH) definitions from Venables et al. (2012). Frontal positions shown on the maps correspond to the mean positions over the trip period of the corresponding foraging group. PFZ: Polar Frontal Zone; PF: Polar Front; AAZ: Antarctic Zone; SACCF: Southern ACC Front; SB: Southern ACC Boundary

In the PFZ, low water temperature appeared to play a more important role for wiggles occurrence than the temperature gradient (Fig. 6 a,b). The logistic regression model showed that wiggle occurrence was greater at negative water temperature gradients for Brooding I birds, and increasing with positive gradient for Brooding II birds (Fig 6c,d). Correlations were stronger for Brooding I than for Brooding II birds. Risk score plots indicated better model discrimination performances for conditions of wiggles absence than of wiggles presence for all birds, and reduced performances for grouped birds compared to the analysis of single birds.

\section{Body mass gain of tracked penguins}

Brooding II birds had highest body mass gains per day as well as in relation to horizontal and vertical distances travelled. Brooding I birds showed higher mass gains per day and distances travelled than the Incubation group (Table 4).

\section{DISCUSSION}

This is the first study to investigate how a deep diving avian marine predator changes its foraging 

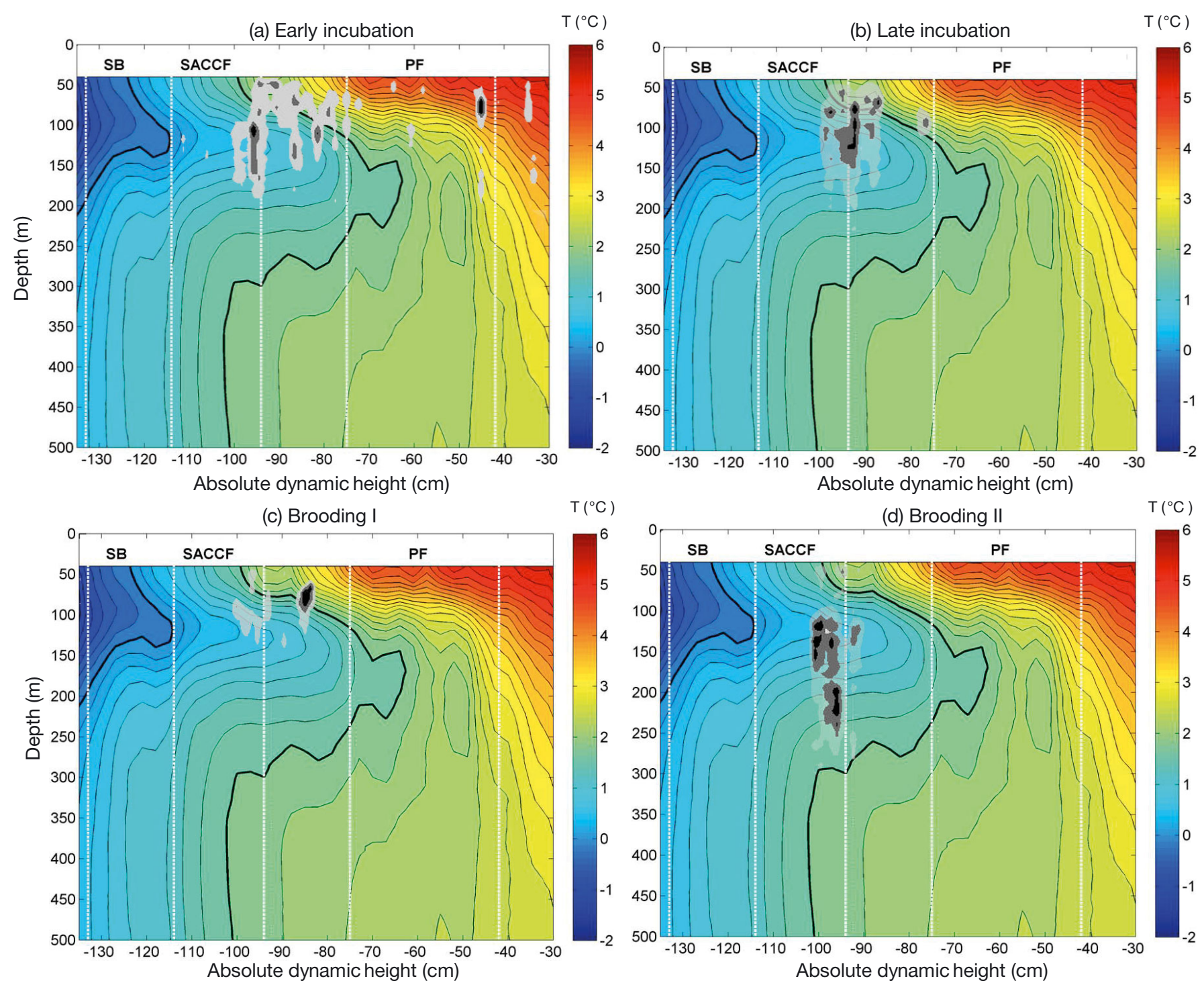

Fig. 4. Aptenodytes patagonicus. Kernel densities of bottom times for the different foraging groups (a-d). Density contours encompass 20,50 and $90 \%$ of the bottom time distributions. Temperature profiles on SSH and depth with ACC front limitations from Venables et al. (2012)

behaviour and habitat use at a fine spatial scale, both vertically and horizontally. The major features of our study are: (1) King penguin foraging behaviour showed different horizontal and vertical patterns over the summer season, presumably in response to changing energetic constraints related to their breeding phase. Foraging trips during incubation extended to the $\mathrm{PF}$, whereas brooding birds foraged exclusively south of the PF in AAZ and SACCF waters. (2) Diving behaviour was correlated with the thermal structure of the water column, with the vertical temperature gradient and depth appearing to play important roles for the separation of different vertical foraging niches. (3) Structure in the hydrological environment south of the PF may allow foraging strat- egy adjustment in relation to changing constraints, and may offer important flexibility for king penguins in the context of environmental variability.

\section{Foraging areas in relation to frontal zones}

Areas used for foraging by king penguins changed over the course of the summer season. Birds explored the PF during early incubation and the waters between the PF and the SACCF later in the summer season. For seabirds, changes in foraging trip duration at different times of the breeding cycle are known to occur and are thought to be the result of changing time constraints arising from the need to supply the chick 

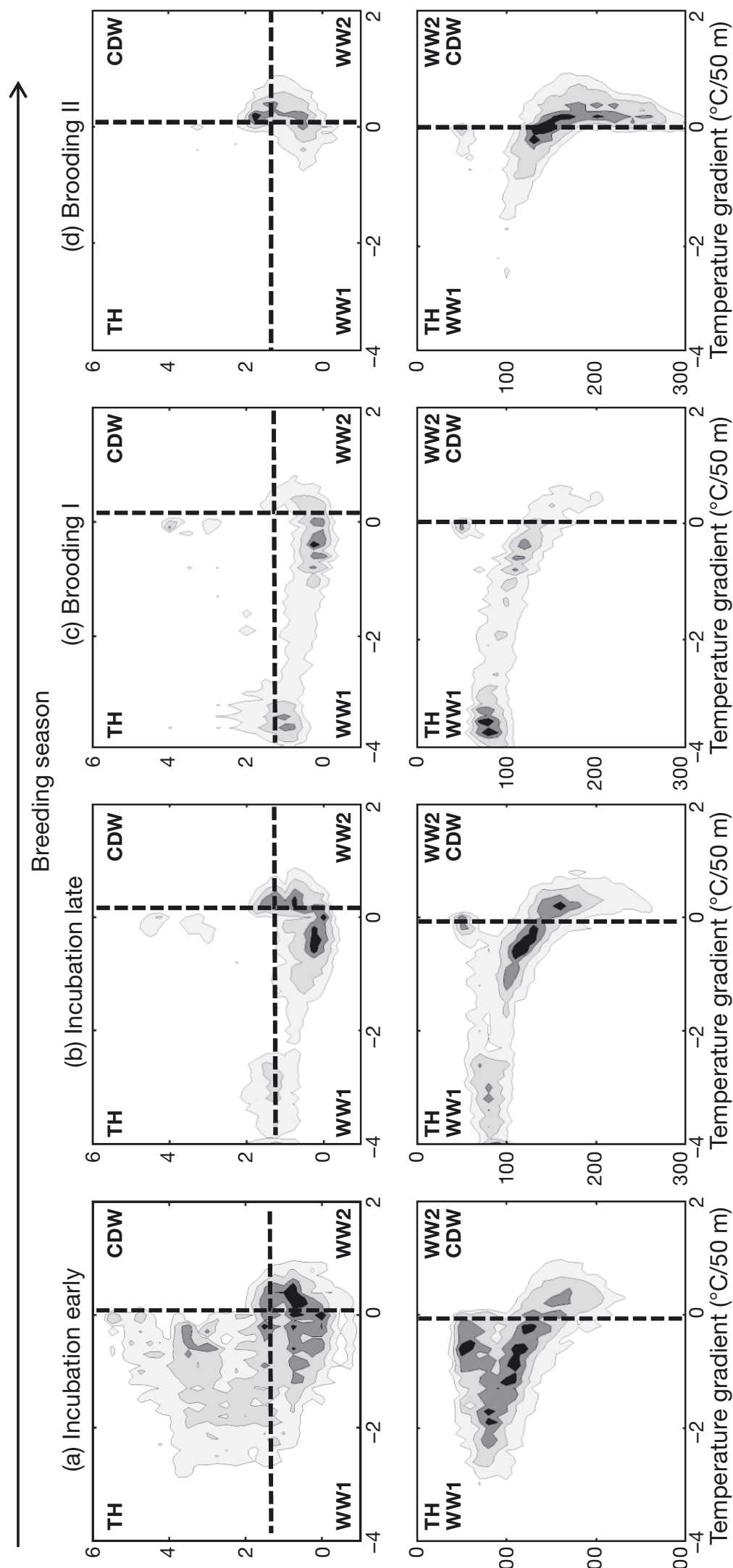

Temperature $\left({ }^{\circ} \mathrm{C}\right)$

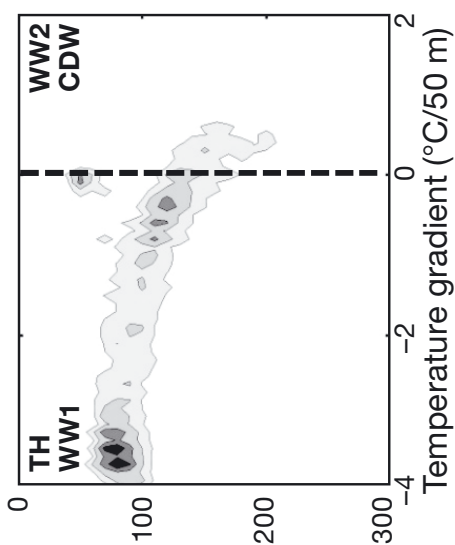

รี ษ

평요

in

$\wedge$ दี

क : च

至

$=0$

范:

ข 웜

罗

명

웅

¿

तै हैं

赵

일

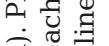

\%

तथ

월 \&

ธ.

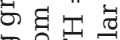

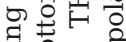

웡

过

考

屯ํํㄹ

कृष

글류 중

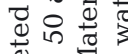
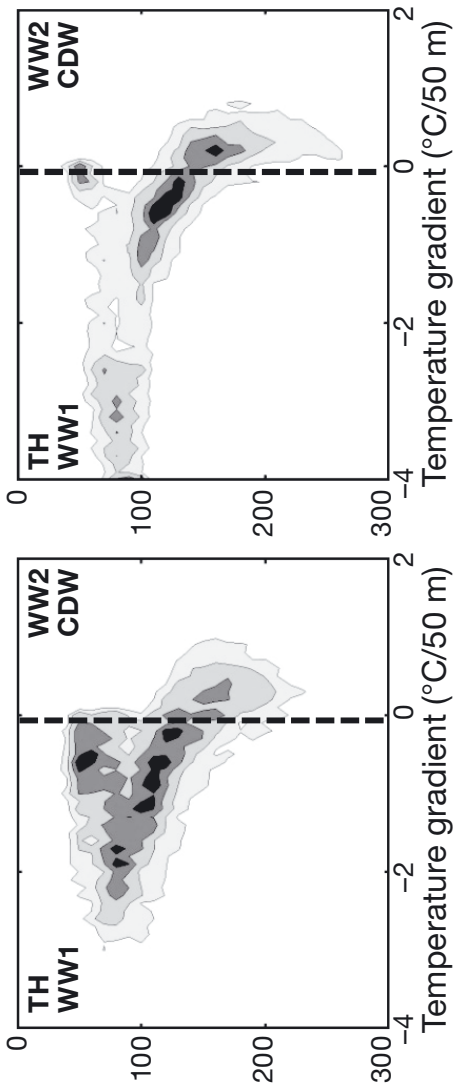

Depth $(\mathrm{m})$ with food (Bost et al. 1997, Charrassin et al. 1999, Lescroël \& Bost 2005). However, in contrast with the situation at South Georgia, king penguins breeding at other locations have not been reported as changing their foraging areas between incubation and brooding (Bost et al. 1997, Guinet et al. 1997, Sokolov et al. 2006). The accessible region to the north of South Georgia is influenced by 2 major ACC fronts, both representing potential areas of increased mesoscale variability (Trathan et al. 1997, 2000, Moore et al. 1999b, Thorpe et al. 2002, Meredith et al. 2003), and, therefore, the possibility of alternative foraging locations for marine predators. The role of the PF has already been reported for king penguins breeding at South Georgia (Trathan et al. 2008, Scheffer et al. 2010) and at other locations (Bost et al. 1997, 2009, Moore et al. 1999a, Charrassin \& Bost 2001, Sokolov et al. 2006). At South Georgia, the AAZ and SACCF appear to provide alternative foraging areas closer to the colony. It may allow short foraging trips with low travel costs for birds with high time and energy constraints, as shown by brooding birds, and may, therefore, play a key role for king penguins.

The importance of the SACCF for the Scotia Sea ecosystem has been emphasised in previous studies (Thorpe et al. 2002, 2004, Ward et al. 2002, Murphy et al. 2004;) due to nutrient enrichment resulting in increased phyto- and zooplankton development, possibly resulting in increased myctophid densities associated with these more productive waters. In the AAZ, the meeting of Antarctic waters with warmer PFZ waters as well as the presence of SACCF eddies 

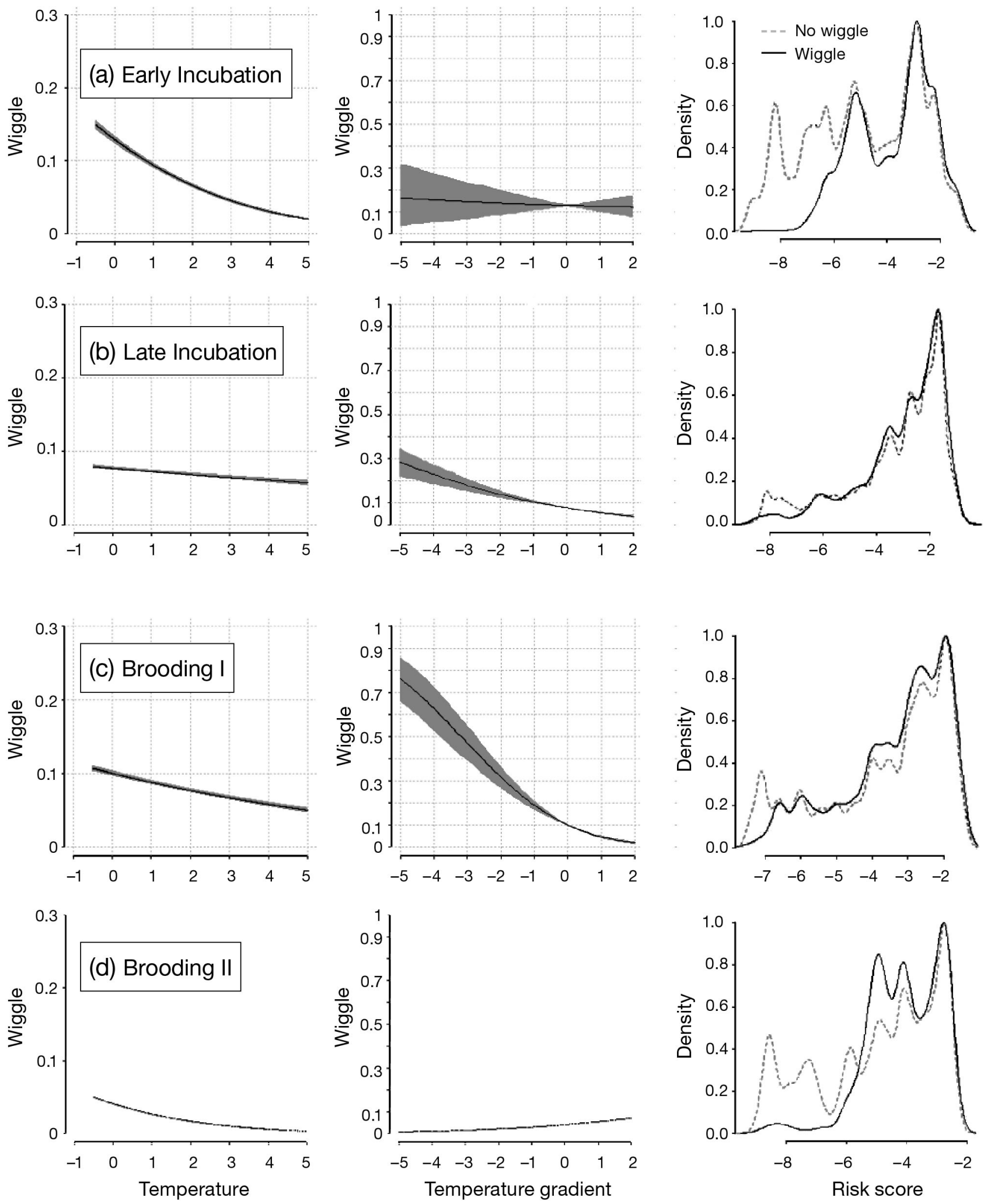

Fig. 6. Aptenodytes patagonicus. Wiggles occurrence as a function of water temperature and temperature gradient, and corresponding risk score plots for model discrimination performance. Output of the logistic regression model and risk score plots for (a) 1 Early Incubation and (b) 1 Late Incubation bird. Early Incubation includes data from only within PF and PFZ waters, Late Incubation includes data from the entire trip. (c,d) Model output and risk score plot for (c) 1 Brooding I and (d) 1 Brooding II bird 
Table 4. Aptenodytes patagonicus. Body mass at start and end of foraging trips as well as total body mass gain per day and per distance travelled for individuals tracked in 2007. $\mathrm{HD}=$ horizontal distance; $\mathrm{VD}=$ vertcal distance

\begin{tabular}{|c|c|c|c|c|c|}
\hline \multirow{2}{*}{ Bird ID } & \multirow{2}{*}{$\begin{array}{c}\text { Start weight } \\
(\mathrm{kg})\end{array}$} & \multirow{2}{*}{$\begin{array}{c}\text { End weight } \\
(\mathrm{kg})\end{array}$} & \multicolumn{3}{|c|}{ _ Mass gain } \\
\hline & & & $\left(\mathrm{kg} \mathrm{d}^{-1}\right)$ & (kg per $100 \mathrm{~km} \mathrm{HD)}$ & (kg per $100 \mathrm{~km} \mathrm{VD)}$ \\
\hline \multicolumn{6}{|c|}{ Late Incubation } \\
\hline C5 & 11.4 & 15.4 & 0.23 & 0.25 & 0.07 \\
\hline $\mathrm{C} 7$ & 11.4 & 17.0 & 0.28 & 0.34 & 0.09 \\
\hline $\mathrm{C} 9$ & 11.0 & 14.2 & 0.14 & 0.19 & 0.05 \\
\hline $\mathrm{C} 10$ & 11.8 & 14.6 & 0.21 & 0.24 & 0.06 \\
\hline Mean \pm SE & $11.4 \pm 0.2$ & $15.3 \pm 0.6$ & $0.21 \pm 0.03$ & $0.26 \pm 0.04$ & $0.07 \pm 0.01$ \\
\hline \multicolumn{6}{|l|}{ Brooding I } \\
\hline H5 & 13.8 & 15.8 & 0.33 & 0.33 & 0.08 \\
\hline H9 & 13.8 & 16.9 & 0.50 & 0.55 & no TDR \\
\hline P3 & 12.1 & 15.1 & 0.33 & 0.32 & 0.10 \\
\hline P5 & 14.1 & 17.0 & 0.42 & 0.35 & 0.12 \\
\hline Mean \pm SE & $13.5 \pm 0.5$ & $16.2 \pm 0.4$ & $0.39 \pm 0.04$ & $0.39 \pm 0.06$ & $0.10 \pm 0.01$ \\
\hline \multicolumn{6}{|l|}{ Brooding II } \\
\hline H3 & 14.0 & 16.8 & 0.55 & 0.57 & 0.13 \\
\hline H6 & 13.0 & 15.8 & 0.51 & 0.57 & no TDR \\
\hline $\mathrm{P} 4$ & 13.8 & 15.9 & 0.35 & 0.41 & 0.09 \\
\hline P10 & 12.0 & 14.5 & 0.46 & 0.58 & 0.10 \\
\hline $\mathrm{T} 4$ & 15.1 & 17.9 & 0.58 & 0.44 & 0.14 \\
\hline Mean \pm SE & $13.6 \pm 0.5$ & 16.0 & $0.49 \pm 0.04$ & $0.51 \pm 0.04$ & $0.12 \pm 0.01$ \\
\hline
\end{tabular}

(Thorpe et al. 2002, Meredith et al. 2003) may create areas of strong thermal gradients, where myctophids may aggregate (Brandt et al. 1981, Kozlov et al. 1991). Reduced vertical mixing in the AAZ compared to adjacent frontal areas may increase the stability of such thermal structures, therefore favouring associated prey patches (Spear et al. 2001).

King penguins have already been reported to use mesoscale oceanographic features for non-random directed foraging during incubation at South Georgia (Trathan et al. 2008, Scheffer et al. 2010) and at Crozet islands (Cotté et al. 2007). Seasonal changes between foraging areas associated with different larger-scale oceanographic features of elevated mesoscale activity support the hypothesis that king penguin alter their foraging behaviour at different spatial and temporal scales.

\section{Targeted foraging niches in the water column}

Our detailed analysis of the time spent at the bottom of the dives, relative to frontal zones and to thermal structures in the water column, allowed us to determine the water masses explored by king penguins over the summer season, and how birds adjust their foraging niches according to breeding constraints.

During December and January, incubating birds foraged in the SACCF, the AAZ and the $\mathrm{PF}$, and targeted various thermal structures at different depths in the water column. Enhanced vertical mixing in frontal areas (Spear et al. 2001) may lead to increased spatial and temporal variability in thermal structures and associated prey resources. Such dynamic prey distributions may be reflected by the less consistent targeting of specific depthtemperature-gradient patterns of birds foraging in the PF compared to in the AAZ, and only weak correlation of wiggle occurrence with specific temperature gradients.

Late Incubation and Brooding I birds mainly foraged in AAZ waters. Brooding I birds targeted shallow WW in close proximity to the thermocline, and wiggles occurrence was correlated with strong thermal gradients. The importance of sub-thermocline prey aggregations has already been reported for dolphins (Scott \& Chivers 2009), tuna (Schaefer et al. 2007) and sunfish (Cartamil \& Lowe 2004), and appears to be confirmed for king penguins foraging in the AAZ. Collins et al. $(2008,2012)$ found that certain myctophid species can be present at shallow depths during daytime in the AAZ in the area to the north of South Georgia. Strong thermal gradients of high stability may represent suitable conditions for stable myctophid aggregations at shallow depths, which have been reported previously associated with warm-core rings in the Gulf Stream (Conte et al. 1986) and in the equatorial Atlantic Ocean, with tuna 
also exploiting these aggregations (Marchal \& Lebourges 1996, Bard et al. 2002). The diving behaviour of Brooding I birds may indicate the presence of such permanent myctophid layers at shallow depths of 70 to $110 \mathrm{~m}$ in the Scotia Sea, even though this has so far only been reported from more temperate regions. However, this hypothesis remains speculative as independent prey data was not available for our study.

Brooding II birds showed significantly deeper dives than the other groups, mainly targeting waters with weak positive temperature gradients at the transition between deep WW and CDW in the SACCF. High body mass gains despite increased dive depths and reduced bottom times suggest increased foraging efficiency in these deep waters. Deep and long dives reported from king penguins at Crozet in autumn (Charrassin et al. 1998, 2002, Halsey et al. 2010) suggest seasonal changes in targeted prey similar to those observed at South Georgia for Brooding II birds. At Crozet, king penguins appear to compensate increased costs for deeper dives in autumn by longer bottom times (Charrassin et al. 2002, Halsey et al. 2010). At South Georgia, king penguins seem to be able to increase foraging efficiency at the bottom of dives. The foraging area targeted by Brooding II birds may provide particular conditions of highly profitable prey resources at great depths, potentially enhanced by the higher nutrient content in areas with the SACCF influx into the Scotia Sea (Ward et al. 2002).

\section{Thermal structure of the water column and foraging}

The thermal structure of the water column and depth appeared to play a crucial role for the separation of foraging niches and the expression of different foraging patterns, especially with increasing constraints on the animals. Relative water structures have been suggested to play an important role for vertical movements of other diving predators such as tuna and billfish (Brill et al. 1993, Brill \& Lutcavage 2001), sunfish (Cartamil \& Lowe 2004), dolphins (Scott \& Chivers 2009) and basking sharks (Sims et al. 2005). Foraging tuna and associated tropical seabirds have been reported to be more abundant in non-frontal areas characterized by lower vertical mixing and higher stability of vertical thermal structures (Owen 1981, Spear et al. 2001). King penguins are diving predators that target similar prey; they may, therefore, rely on the same criteria for favourable foraging habitats and show similar affinity with well structured waters, possibly reflected by targeting distinct niches in non-frontal or border areas by brooding birds. In addition to the importance of frontal zones for Southern Ocean marine predators (Bost et al. 2009), non-frontal or boundary areas with a higher stability of vertical thermal structures may also play a key role for diving predators such as king penguins, especially when constraints limit flexible travel times and behavioural adaptations to dynamic conditions at fronts.

The vertical temperature gradient appeared to be a main factor for foraging niche adjustment and explaining differences in prey pursuit behaviour (wiggle occurrence). Thermal gradients are locations of enhanced biological activity (Thomas \& Emery 1988, Lima et al. 2002), resulting in the accumulation of biomass for various trophic levels, ranging from planktonic organisms to mesopelagic fish and ultimately upper trophic level predators. Being one of the most pronounced vertical temperature gradients in the ocean, the thermocline has already been suggested as an important feature for king penguins at Crozet (Charrassin \& Bost 2001) as well as for other marine predators foraging in the Southern Ocean (Boyd \& Arnbom 1991, Biuw et al. 2007) and in more temperate regions (Cayre \& Marsac 1993, Kitagawa et al. 2000, Spear et al. 2001, Weng et al. 2009, Sepulveda et al. 2010). Our study underlines the crucial role of the thermocline for foraging king penguins breeding at South Georgia. It also demonstrates the possibility that king penguins have alternate efficient foraging strategies for exploiting water masses where thermal gradients do not seem to be the main factor governing prey distribution.

Our regression models have revealed some insights into the effect of thermal properties of the water column on king penguins foraging. However, variable regression coefficients between individual birds as well as the prevalence of Brooding I and Brooding II patterns on identical trip departure dates underline the fact that foraging strategies might not only relate to particular environmental conditions. Behavioural plasticity and individual factors (Svanback \& Bolnick 2005, Sargeant et al. 2007) such as detailed breeding constraints, fitness and prior experience may also play a role. Lower model performances for wiggle presence than absence may result from the fact that favourable foraging conditions for king penguins are not only determined by the thermal structure of the water column, but may also be influenced by other factors governing prey distribution in a given environment such as stochastic processes and prey behaviour. 


\section{King penguins' foraging and environmental variability}

Foraging behaviour of king penguins breeding at South Georgia appears to be structured both horizontally and vertically. Penguins targeted different foraging areas depending on their breeding constraints, and adjusted their foraging activity in the water column. So far such strong habitat selection and the presence of alternative foraging niches have not been reported for king penguins from other locations. Patterns described from Crozet suggest changes in foraging characteristics over the summer season similar to those described at South Georgia, with shortening of foraging trips and increasing dive depths. However, penguins in both the incubation and brooding stage target the $\mathrm{PF}$, and foraging patterns appear less diverse than those of king penguins at South Georgia with respect to trip characteristics, diving behaviour and the targeting of distinct niches in the water column (Charrassin et al. 1998, 2002, Charrassin \& Bost 2001). This may suggest that alternative foraging areas closer to the colony, as reported from South Georgia, are not available at Crozet.

For king penguins breeding north of the PF (i.e. Crozet, Marion Island), the geographically nearest profitable myctophid aggregations may be found at accessible depths mostly at the PF and its northern edges, as myctophid species targeted by king penguins are known to increase in depth northwards of the PF (S. Fielding pers. comm.). This means that penguins breeding in these locations may depend to a higher degree on the PF. Predicted declines of king penguins due to environmental variability (Barbraud et al. 2008, Le Bohec et al. 2008, Péron et al. 2012) and in case of shifts in the PF may, therefore, only relate to areas where the animals are highly dependent on the PF due to the lack of alternative foraging areas. Such predictions might be of lesser value for king penguins breeding at South Georgia.

King penguins at South Georgia appear to be able to exploit profitable prey resources at the southern edge and south of the $\mathrm{PF}$, either in terms of reduced depth in the AAZ or of increased profitability per catch effort at the bottom in SACCF waters. The area south of the PF may offer an elevated degree of foraging habitat segmentation to king penguins, as other structures than the PF may provide for profitable prey resources at accessible depths. King penguins from Heard Island, also located south of the PF, appear mainly to forage in the area to the east of the island (Moore et al. 1999a, Wienecke \& Robertson 2006), a location influenced by the southern branch of the PF and the Fawn Trough current (Roquet et al. 2009, van Wijk et al. 2010). Foraging in areas outside or at the southern boundaries of the $\mathrm{PF}$, areas characterized by cold water masses, may produce similar patterns to those at South Georgia. However, studies from Heard Island provide no information on diving behaviour in relation to the thermal structure of the water column, or on segregation of foraging areas.

Oceanography at South Georgia is known to be influenced by ENSO (El Niño - Southern Oscillation) and SAM (Southern Annular Mode) as well as more direct atmospheric processes (Trathan \& Murphy 2002, Meredith et al. 2008). However, different time lags between these events and the response in oceanography at South Georgia occur (Meredith et al. 2008), as well as temporal variation in the connections within the Scotia Sea ecosystem (Murphy et al. 2007). Our study includes reports of only one season per foraging group. Therefore, it remains open as to whether the patterns observed are a constant element in the foraging strategy of king penguins breeding at South Georgia, or whether they are a response to particular conditions during our study years. Nevertheless, the oceanographic patterns observed during our study appear to be consistent with general patterns described in the area to the north of South Georgia (Trathan et al. 1997, 2000, Thorpe et al. 2002, Meredith et al. 2003, Brandon et al. 2004). Also, the temporal and spatial scales of the oceanographic features considered exceed the duration of the tracked foraging trips. Low sample sizes of the different foraging groups may raise questions about conclusions on general behavioural patterns at a population level. Even so, the foraging patterns observed during brooding indicate the presence of optional foraging niches close to shore at South Georgia, allowing foraging of potentially increased efficiency, at least in some years. This might also play a key role in potential responses of king penguins to environmental changes (Forcada \& Trathan 2009), as optional foraging niches may allow them to better adjust foraging behaviour in response to the prevailing oceanographic conditions.

Acknowledgements. This work is a contribution to the BAS Ecosystems programme, jointly funded by BAS and CNRS. The authors are grateful to C. Bishop for the provision of waterproof housings for the NavSys Track-Tag devices and to $\mathrm{H}$. Venables and S. Thorpe for advice on the oceanography around South Georgia. M. Authier provided help with data analysis, and constructive comments that improved the manuscript. We thank J. Edmonston for help with data organisation and preparation, and C. Thomas for assistance with data collection in the field. Four anonymous reviewers provided helpful comments that greatly improved the manuscript. 


\section{LITERATURE CITED}

Barbraud C, Weimerskirch H, Bost CA, Forcada J, Trathan P, Ainley D (2008) Are king penguin populations threatened by Southern Ocean warming? Proc Natl Acad Sci USA 105:E38

Bard FX, Kouamé B, Hervé A (2002) Schools of large yellowfin (Thunnus albacares) concentrated by foraging on a monospecific layer of Cubiceps pauciradiatus, observed in the eastern tropical Atlantic. Coll Vol Sci Pap ICCAT 54:33-41

Belkin IM, Gordon AL (1996) Southern Ocean fronts from the Greenwich meridian to Tasmania. J Geophys Res 101:3675-3696

Biuw M, Boehme L, Guinet C, Hindell M and others (2007) Variations in behavior and condition of a Southern Ocean top predator in relation to in situ oceanographic conditions. Proc Natl Acad Sci USA 104:13705-13710

Bost CA, Georges JY, Guinet C, Cherel Y and others (1997) Foraging habitat and food intake of satellite-tracked king penguins during the austral summer at Crozet Archipelago. Mar Ecol Prog Ser 150:21-33

> Bost CA, Zorn T, Le Maho Y, Duhamel G (2002) Feeding of diving predators and diel vertical migration of prey: King penguins' diet versus trawl sampling at Kerguelen Islands. Mar Ecol Prog Ser 227:51-61

> Bost CA, Handrich Y, Butler PJ, Fahlman A, Halsey LG, Woakes AJ, Ropert-Coudert Y (2007) Changes in dive profiles as an indicator of feeding success in king and Adélie penguins. Deep-Sea Res II 54:248-255

Bost CA, Cotté C, Bailleul F, Cherel Y and others (2009) The importance of oceanographic fronts to marine birds and mammals of the southern oceans. J Mar Syst 78:363-376

Boyd IL, Arnbom T (1991) Diving behavior in relation to water temperature in the southern elephant sealforaging implications. Polar Biol 11:259-266

Brandon MA, Naganobu M, Demer DA, Chernyshkov P and others (2004) Physical oceanography in the Scotia Sea during the CCAMLR 2000 survey, austral summer 2000. Deep-Sea Res II 51:1301-1321

Brandt SB, Parker RR, Vaudrey DJ (1981) Physical and biological description of warm core eddy J during September-October, 1979. Rep Div Fish Oceanogr CSIRO Aust. 126:1-52

Brill RW, Lutcavage ME (2001) Understanding environmental influences on movements and depth distributions of tunas and billfishes can significantly improve population assessments. In: Sedberry GR (ed) Island in the stream: oceanography and fisheries of the Charleston Bump, Vol 25. Amer Fisheries Soc, Bethesda, MD, p 179-198

> Brill RW, Holts DB, Chang RKC, Sullivan S, Dewar H, Carey FG (1993) Vertical and horizontal movements of striped marlin (Tetrapturus audax) near the Hawaiian Islands, determined by ultrasonic telemetry, with simultaneous measurement of oceanic currents. Mar Biol 117:567-574

> Cartamil DP, Lowe CG (2004) Diel movement patterns of ocean sunfish Mola mola off southern California. Mar Ecol Prog Ser 266:245-253

Cayre P, Marsac F (1993) Modelling the yellowfin tuna (Thunnus albacares) vertical distribution using sonic tagging results and local environmental parameters. Aquat Living Resour 6:1-14

Charrassin JB, Bost CA (2001) Utilisation of the oceanic habitat by king penguins over the annual cycle. Mar Ecol Prog Ser 221:285-298
Charrassin JB, Bost CA, Putz K, Lage L, Dahier T, Zorn T, Le Maho Y (1998) Foraging strategies of incubating and brooding king penguins Aptenodytes patagonicus. Oecologia 114:194-201

Charrassin JB, Bost CA, Pütz K, Lage J, Dahier T, Le Maho $Y$ (1999) Changes in depth utilization in relation to the breeding stage: a case study with the King Penguin Aptenodytes patagonicus. Mar Ornithol 27:43-47

> Charrassin JB, Le Maho Y, Bost CA (2002) Seasonal changes in the diving parameters of king penguins (Aptenodytes patagonicus). Mar Biol 141:581-589

Cherel Y, Ridoux V (1992) Prey species and nutritive value of food fed during summer to King Penguin Aptenodytes patagonica chicks at Possession Island, Crozet Archipelago. Ibis 134:118-127

Collins MA, Xavier JC, Johnston N, North A and others (2008) Patterns in the distribution of myctophid fish in the northern Scotia Sea ecosystem. Polar Biol 31:837-851

Collins M, Stowasser G, Fielding S, Shreeve R and others (2012) Latitudinal and bathymetric patterns in the distribution and abundance of mesopelagic fish in the Scotia Sea. Deep-Sea Res II 59-60:189-198

Conte MH, Bishop JKB, Backus RH (1986) Nonmigratory, 12-Khz, deep scattering layers of Sargasso Sea origin in warm-core rings. Deep-Sea Res Part A33:1869-1884

Cotté C, Park YH, Guinet C, Bost CA (2007) Movements of foraging king penguins through marine mesoscale eddies. Proc Biol Sci 274:2385-2391

Deacon GER (1933) A general account of the hydrology of the South Atlantic Ocean. Discovery Report VII:177-238

Fielding S, Watkins JL, Collins MA, Enderlein P, Venables HJ (2012) Acoustic determination of the distribution of fish and krill across the Scotia Sea in spring 2006, summer 2008 and autumn 2009. Deep-Sea Res II 59-60: $173-188$

- Forcada J, Trathan PN (2009) Penguin responses to climate change in the Southern Ocean. Glob Change Biol 15: 1618-1630

Franks PJS (1992) Sink or swim: accumulation of biomass at fronts. Mar Ecol Prog Ser 82:1-12

Guinet C, Koudil M, Bost CA, Durbec JP, Georges JY, Mouchot MC, Jouventin P (1997) Foraging behaviour of satellite-tracked king penguins in relation to sea-surface temperatures obtained by satellite telemetry at Crozet Archipelago, a study during 3 austral summers. Mar Ecol Prog Ser 150: 11-20

Halsey L, Bost C, Handrich Y (2007) A thorough and quantified method for classifying seabird diving behaviour. Polar Biol 30:991-1004

> Halsey LG, Butler PJ, Fahlman A, Bost CA, Handrich Y (2010) Changes in the foraging dive behaviour and energetics of king penguins through summer and autumn: a month by month analysis. Mar Ecol Prog Ser 401: 279-289

> Hanuise N, Bost CA, Huin W, Auber A, Halsey LG, Handrich Y (2010) Measuring foraging activity in a deepdiving bird: comparing wiggles, oesophageal temperatures and beak-opening angles as proxies of feeding. J Exp Biol 213:3874-3880

> Hull CL, Hindell MA, Michael K (1997) Foraging zones of royal penguins during the breeding season, and their association with oceanographic features. Mar Ecol Prog Ser 153:217-228

Hulley PA (1981) Results of the research cruises of FRV 'Walther Herwig' to South America. LVIII. Family Myc- 
tophidae (Osteichthyes, Myctophiformes). Arch FischWiss 31:1-300

Kitagawa T, Nakata H, Kimura S, Itoh T, Tsuji S, Nitta A (2000) Effect of ambient temperature on the vertical distribution and movement of Pacific bluefin tuna Thunnus thynnus orientalis. Mar Ecol Prog Ser 206:251-260

Kozlov AN, Shrust KV, Zemsky AV (1991) Seasonal and inter-annual variability in the distribution of Electrona carlsbergi in the southern Polar Front area (the area to the north of South Georgia is used as an example). Selected Scientific Papers (SC-CAMLR-SSP/7). CCAMLR, Hobart, p 337-367

Le Bohec C, Durant JM, Gauthier-Clerc M, Stenseth NC and others (2008) King penguin population threatened by Southern Ocean warming. PNAS 105:2493-2497

> Lescroël A, Bost CA (2005) Foraging under contrasting oceanographic conditions: the gentoo penguin at Kerguelen Archipelago. Mar Ecol Prog Ser 302:245-261

Lima ID, Olson DB, Doney SC (2002) Biological response to frontal dynamics and mesoscale variability in oligotrophic environments: biological production and community structure. J Geophys Res 107:3111 doi:10.1029/2000 JC000393

Lutjeharms JRE, Walters NM, Allanson R (1985) Oceanic frontal systems and biological enhancement. In: Siegfried WR, Condy PR, Laws RM (eds) Antarctic nutrient cycles and food webs. Springer Berlin. p 11-21

> Marchal E, Lebourges A (1996) Acoustic evidence for unusual diel behaviour of a mesopelagic fish (Vinciguerria nimbaria) exploited by tuna. ICES J Mar Sci 53: 443-447

$>$ McCafferty DJ, Currie J, Sparling CE (2007) The effect of instrument attachment on the surface temperature of juvenile grey seals (Halichoerus grypus) as measured by infrared thermography. Deep-Sea Res II 54:424-436

> Meredith MP, Watkins JL, Murphy EJ, Ward P and others (2003) Southern ACC Front to the northeast of South Georgia: pathways, characteristics, and fluxes. J Geophys Res 108:3162 doi:10.1029/2001JC001226

Meredith MP, Murphy EJ, Hawker EJ, King JC, Wallace MI (2008) On the interannual variability of ocean temperatures around South Georgia, Southern Ocean: forcing by El Niño/Southern Oscillation and the Southern Annular Mode. Deep-Sea Res II 55:2007-2022

Moore GJ, Wienecke B, Robertson G (1999a) Seasonal change in foraging areas and dive depths of breeding king penguins at Heard Island. Polar Biol 21:376-384

Moore JK, Abbott MR, Richman JG (1999b) Location and dynamics of the Antarctic Polar Front from satellite sea surface temperature data. J Geophys Res C 104: 3059-3073

> Murphy EJ, Watkins JL, Meredith MP, Ward P, Trathan PN, Thorpe SE (2004) Southern Antarctic Circumpolar Current Front to the northeast of South Georgia: Horizontal advection of krill and its role in the ecosystem. J Geophys Res 109:C01029 doi:10.1029/2002JC001522

Murphy EJ, Watkins JL, Trathan PN, Reid K and others (2007) Spatial and temporal operation of the Scotia Sea ecosystem: a review of large-scale links in a krill centred food web. Philos Trans R Soc Lond B362:113-148

> Olsson O, North AW (1997) Diet of the King Penguin Aptenodytes patagonicus during 3 summers at South Georgia. Ibis 139:504-512

> Orsi AH, Whitworth T, Nowlin WD (1995) On the meridional extent and fronts of the Antarctic Circumpolar Current.
Deep-Sea Res I 42:641-673

Owen RW (1981) Fronts and eddies in the sea: mechanisms, interactions and biological effects. In: Longhurst AR (ed) Analysis of marine ecosystems. Academic Press, San Francisco, CA, p 197-233

Pakhomov EA, Perissinotto R, McQuaid D (1996) Prey composition and daily rations of myctophid fishes in the Southern Ocean. Mar Ecol Prog Ser 134:1-14

Péron C, Weimerskirch H, Bost CA (2012) Projected poleward shift of king penguins' (Aptenodytes patagonicus) foraging range at the Crozet Islands, southern Indian Ocean. Proc R Soc Lond B 279:2515-2523

Pütz K, Wilson RP, Charrassin JB, Raclot T and others (1998) Foraging strategy of king penguins (Aptenodytes patagonicus) during summer at the Crozet Islands. Ecology 79:1905-1921

Rintoul SR, Hughes CW, Olbers D (2001) The Antarctic Circumpolar Current System. In: Siedler G, Church J, Gould J (eds) Ocean circulation and climate: observing and modelling the global ocean. Elsevier, New York, p 271-302

Rodhouse PG, Prince PA, Trathan PN, Hatfield EMC and others (1996) Cephalopods and mesoscale oceanography at the Antarctic Polar Front: satellite tracked predators locate pelagic trophic interactions. Mar Ecol Prog Ser 136:37-50

> Ropert-Coudert Y, Kato A, Wilson R, Cannell B (2006) Foraging strategies and prey encounter rate of free-ranging little penguins. Mar Biol 149:139-148

$>$ Roquet F, Park YH, Guinet C, Bailleul F, Charrassin JB (2009) Observations of the Fawn Trough Current over the Kerguelen Plateau from instrumented elephant seals. J Mar Syst 78:377-393

Royston P, Altman DG (2010) Visualizing and assessing discrimination in the logistic regression model. Stat Med 29: 2508-2520

Sargeant BL, Wirsing AJ, Heithaus MR, Mann J (2007) Can environmental heterogeneity explain individual foraging variation in wild bottlenose dolphins (Tursiops sp.)? Behav Ecol Sociobiol 61:679-688

> Schaefer KM, Fuller DW, Block BA (2007) Movements, behavior, and habitat utilization of yellowfin tuna (Thunnus albacares) in the northeastern Pacific Ocean, ascertained through archival tag data. Mar Biol 152:503-525

Scheffer A, Trathan PN, Collins M (2010) Foraging behaviour of king penguins (Aptenodytes patagonicus) in relation to predictable mesoscale oceanographic features in the Polar Front Zone to the north of South Georgia. Prog Oceanogr 86:232-245

> Schneider DC (1990) Seabirds and fronts: a brief overview. Polar Res 8:17-21

Scott MD, Chivers SJ (2009) Movements and diving behavior of pelagic spotted dolphins. Mar Mamm Sci 25:137-160

Sepulveda CA, Knight A, Nasby-Lucas N, Domeier ML (2010) Fine-scale movements of the swordfish Xiphias gladius in the Southern California Bight. Fish Oceanogr 19:279-289

Simeone A, Wilson RP (2003) In-depth studies of Magellanic penguin (Spheniscus magellanicus) foraging: can we estimate prey consumption by perturbations in the dive profile? Mar Biol 143:825-831

Simmons SE, Tremblay Y, Costa DP (2009) Pinnipeds as ocean-temperature samplers: calibrations, validations, and data quality. Limnol Oceanogr Methods 7:648-656

Sims DW, Southall EJ, Tarling GA, Metcalfe JD (2005) Habitat-specific normal and reverse diel vertical migration in 
the plankton-feeding basking shark. J Anim Ecol 74: 755-761

Sokolov S, Rintoul SR (2009) Circumpolar structure and distribution of the Antarctic Circumpolar Current fronts: 2. Variability and relationship to sea surface height. J Geophys Res 114:C11019 doi:10.1029/2008JC005248

Sokolov S, Rintoul SR, Wienecke B (2006) Tracking the Polar Front south of New Zealand using penguin dive data. Deep-Sea Res I 53:591-607

Spear LB, Ballance LT, Ainley DG (2001) Response of seabirds to thermal boundaries in the tropical Pacific: the thermocline versus the Equatorial Front. Mar Ecol Prog Ser 219:275-289

Svanback R, Bolnick DI (2005) Intraspecific competition affects the strength of individual specialization: an optimal diet theory method. Evol Ecol Res 7:993-1012

Takahashi A, Sato K, Naito Y, Dunn MJ, Trathan PN, Croxall JP (2004) Penguin-mounted cameras glimpse underwater group behaviour. Proc R Soc Lond B 271:S281-S282

> Thomas AC, Emery WJ (1988) Relationships between nearsurface plankton concentrations, hydrography, and satellite-measured sea surface temperature. J Geophys Res 93:15733-15748

Thorpe SE, Heywood KJ, Brandon MA, Stevens DP (2002) Variability of the southern Antarctic Circumpolar Current front north of South Georgia. J Mar Syst 37:87-105

Thorpe SE, Heywood KJ, Stevens DP, Brandon MA (2004) Tracking passive drifters in a high resolution ocean model: implications for interannual variability of larval krill transport to South Georgia. Deep-Sea Res I 51: 909-920

Trathan PN, Murphy EJ (2002) Sea surface temperature anomalies near South Georgia: relationships with the pacific El Nino regions. J Geophys Res C 107:8075 doi: 10.1029/2000JC000299

Trathan PN, Brandon MA, Murphy EJ (1997) Characterization of the Antarctic Polar Frontal Zone to the north of South Georgia in summer 1994. J Geophys Res 102: 10483-10497

Editorial responsibility: Matthias Seaman, Oldendorf/Luhe, Germany
Trathan PN, Brandon MA, Murphy EJ, Thorpe SE (2000) Transport and structure within the Antarctic Circumpolar Current to the north of South Georgia. Geophys Res Lett 27:1727-1730

- Trathan PN, Bishop C, Maclean G, Brown P, Fleming A, Collins MA (2008) Linear tracks and restricted temperature ranges characterise penguin foraging pathways. Mar Ecol Prog Ser 370:285-294

> van Wijk EM, Rintoul SR, Ronai BM, Williams GD (2010) Regional circulation around Heard and McDonald Islands and through the Fawn Trough, central Kerguelen Plateau. Deep-Sea Res I 57:653-669

> Venables HJ, Meredith MP, Atkinson A, Ward P (2012) Fronts and habitat zones in the Scotia Sea. Deep-Sea Res II 59-60:14-24

> Ward P, Whitehouse M, Meredith M, Murphy E and others (2002) The Southern Antarctic Circumpolar Current Front: physical and biological coupling at South Georgia. Deep-Sea Res I 49:2183-2202

- Weavers BW (1992) Seasonal foraging ranges and travels at sea of little penguins Eudyptula minor, determined by radiotracking. Emu 91:302-317

- Weng KC, Stokesbury MJW, Boustany AM, Seitz AC, Teo SLH, Miller SK, Block BA (2009) Habitat and behaviour of yellowfin tuna Thunnus albacares in the Gulf of Mexico determined using pop-up satellite archival tags. J Fish Biol 74:1434-1449

> Wienecke B, Robertson G (2006) Comparison of foraging strategies of incubating king penguins Aptenodytes patagonicus from Macquarie and Heard islands. Polar Biol 29:424-438

Wilson R, Pütz K, Peters G, Culik B , Scolaro JA, Charrassin JB, Ropert-Coudert Y (1997) Long-term attachment of transmitting and recording devices to penguins and other seabirds. Wildl Soc Bull 25:101-106

Woehler EJ (1995) Consumption of Southern Ocean resources by penguins. In: Dann P, Norman I, Reilly P (eds) The Penguins: ecology and management. Surrey Beatty \& Sons, Chipping Norton, p 267-291

Submitted: June 27, 2011; Accepted: June 18, 2012

Proofs received from author(s): September 17, 2012 